\title{
Evaluation of Notifiable Disease Surveillance System in Centenary District, Zimbabwe, 2016
}

\author{
N. Mairosi ${ }^{1}$, C. Tshuma ${ }^{2}$, T. P. Juru ${ }^{1}$, N. T. Gombe ${ }^{1}$, G. Shambira1, M. Tshimanga ${ }^{1}$ \\ ${ }^{1}$ Department of Community Medicine, University of Zimbabwe, Harare, Zimbabwe \\ ${ }^{2}$ Ministry of Health, Mashonaland Central Provincial Medical Directorate, Bindura, Zimbabwe \\ Email: ngavemairosi@gmail.com,pmdmashcent@gmail.com, ^tjuru@zimfetp.net,ntgombe@gmail.com, \\ gshambira@yahoo.com,tshimangamufuta@gmail.com
}

How to cite this paper: Mairosi, N., Tshuma, C., Juru, T.P., Gombe, N.T., Shambira, G. and Tshimanga, M. (2017) Evaluation of Notifiable Disease Surveillance System in Centenary District, Zimbabwe, 2016. Open Journal of Epidemiology, 7, 251-261. https://doi.org/10.4236/ojepi.2017.73019

Received: April 19, 2017

Accepted: August 8, 2017

Published: August 11, 2017

Copyright $\odot 2017$ by authors and Scientific Research Publishing Inc. This work is licensed under the Creative Commons Attribution International License (CC BY 4.0).

http://creativecommons.org/licenses/by/4.0/

(c) (i) Open Access

\begin{abstract}
Background: Notifiable disease surveillance system (NDSS) data guides immediate action for events of public health importance. In July 2016, 12 patients suspected of typhoid were reported to Centenary District Medical Officer by phone. Following reporting, notification forms (T1) were not submitted to district, hence province did not receive district consolidated report (T2) for the notifications. This implies underreporting of notifiable diseases. Study was conducted to evaluate NDSS in Centenary district. Methods: Using updated Centres for Disease Control and Prevention (CDC) guidelines, descriptive cross sectional study was conducted among health workers sampled from all health facilities in Centenary district. Interviewer administered questionnaire and checklists were used to collect data, assess data quality and resource availability. Epi Info ${ }^{\mathrm{TM}} 7$ generated frequencies and proportions. Results: We interviewed 50 respondents from 13 health facilities and 64\% were females. Health worker knowledge was rated low, $26 \%$ knew whom to notify and $40 \%$ knew forms are completed in triplicate. Reasons for failure to notify notifiable diseases included, unavailability of reporting forms $32 \%$ and lack of reporting guidelines $16 \%$. Ninety-two percent were willing to participate. Four health facilities had at least six standard case definitions. The first two patients were only diagnosed at district level. NDSS information was used to procure antirabies vaccine and implement control measures. Conclusion: NDSS is useful, acceptable, unstable and not sensitive. Failure to notify was mainly due to lack of knowledge on NDSS. We recommend training of health workers and mentoring. Fifteen (IEC) case definitions and reporting guidelines were distributed to five health facilities.
\end{abstract}

\section{Keywords}

Evaluation, Notifiable Disease Surveillance, Centenary, Zimbabwe 


\section{Background}

Public health surveillance is the ongoing, systematic collection, analysis, interpretation and dissemination of data about a health related event for use in public health action to reduce morbidity and mortality and to improve health [1]. Data collected through surveillance assists in guiding health personnel on effective strategies needed in prevention and control especially for epidemic prone diseases. Public Health Surveillance Systems guide immediate action for health events of public health importance, measure disease burden, detect changes in disease occurrence, identify population at risk, monitor trends of disease including detection of outbreaks, guide planning, implementation and evaluation of programmes, evaluate public policy, detect changes in health practices, prioritise allocation of health resources, describe clinical course of disease and provide a basis for epidemiologic research [1].

A notifiable disease is one that is required to be reported to local health officials as soon as it is diagnosed because of infectiousness, severity or frequency of occurrence [2]. In Zimbabwe the Public Health Act established the Notifiable Disease Surveillance System (NDSS) which currently requires reporting of 19 notifiable diseases including Acute Flaccid Paralysis (AFP), Anthrax, Cholera, Hepatitis (all forms), Meningococcal Meningitis, Rabies, Tuberculosis, Typhoid, Viral Haemorrhagic Fever, Severe Acute Respiratory Syndrome (SARS), Human Influenza A, leprosy and yellow fever [3]. The Act allows the Minister to revise the list of notifiable diseases by adding some diseases based on current public health needs for instance addition of SARS.

The system requires that any health worker who comes into contact with a suspected or confirmed notifiable disease should immediately notify the District Medical Officer (DMO) using the fastest method possible such as telephone, radio, email, within 24 hours of diagnosis [4]. Paper based reporting using T1 (data collection tool which is used to collect data at health facility level) notification form for infectious notifiable diseases follows the initial reporting. The health worker at the facility completes the $\mathrm{T} 1 \mathrm{form}$ in triplicate and sends the original form to the district level, the first copy is kept at the health facility and the second copy is used as a laboratory transmittal slip for specimens [4]. The district summarises the notifiable diseases for that month on a T2 form which is sent to the provincial level by the $10^{\text {th }}$ of the following month. The province summarises the T2 forms from all the districts to a provincial T2 form, which is forwarded to the head office by the $24^{\text {th }}$ of each month where a national summary is produced (Figure 1).

In July 2016, suspected cases of typhoid were notified by phone to the DMO of Centenary district, and a line list of 12 cases was completed at the health facility however, the suspected cases were not notified using the $\mathrm{T} 1$ forms hence the consolidated $\mathrm{T} 2$ form was not completed by the district. Though the provincial office requested the district to submit the T2 form and update the District Health Information System 2 (DHIS 2), this was not rectified. Failure to notify 


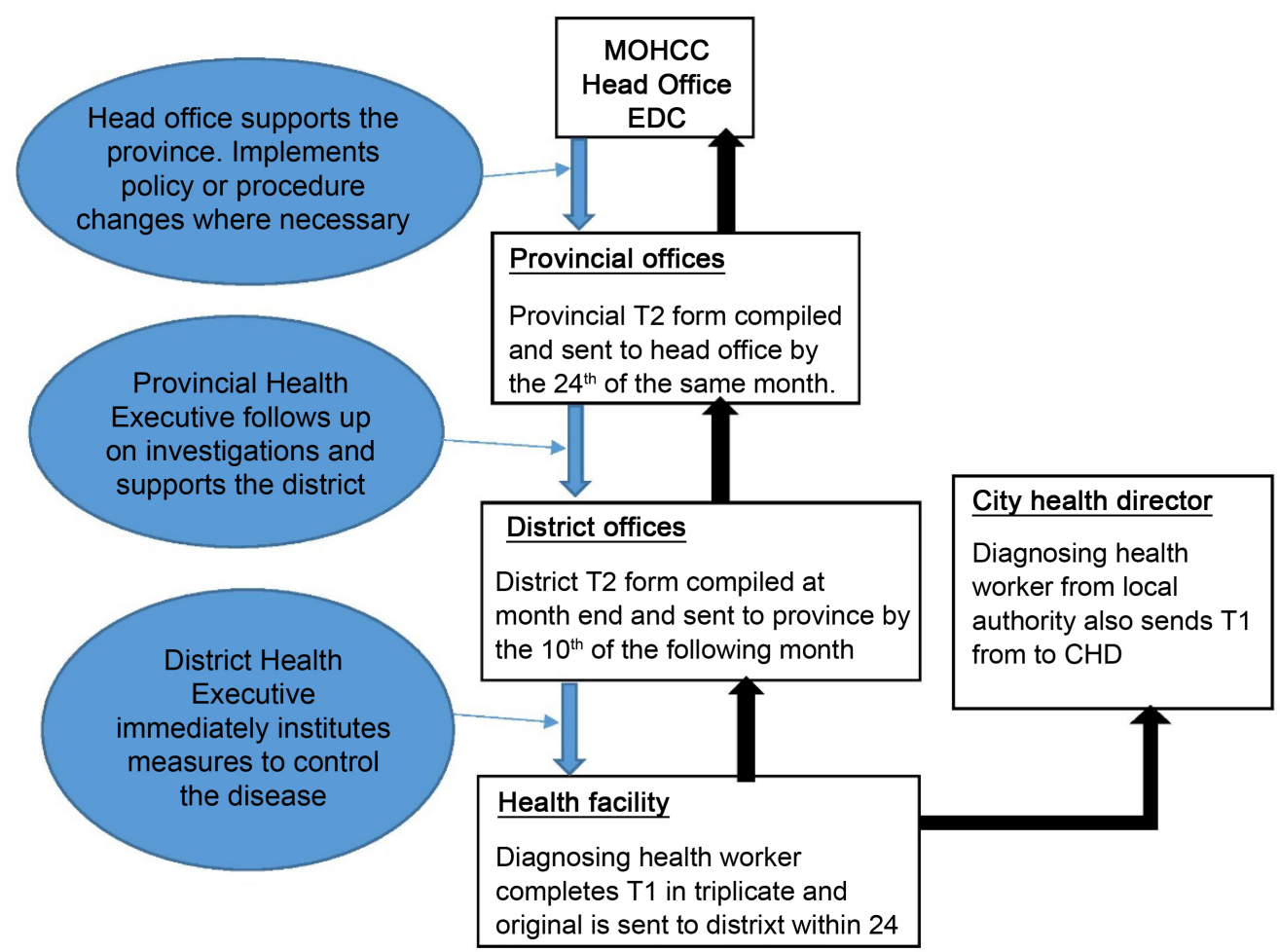

Figure 1. Flow of information in NDSS, adapted from Zimbabwe health information system strategy 2009-2014.

notifiable diseases raises concern to the district and the provincial health management as this implies undereporting of notifiable diseases, and may delay investigation and control of diseases. An evaluation of the Notifiable Disease Surveillance System was carried out in Centenary district, Zimbabwe for the period January to December 2016. The study assessed usefullness of the NDSS, the systems attributes, health care worker knowledge levels and it determined the cost of running the system and reasons for not notifying notifiable diseases.

\section{Methods}

A descriptive cross sectional study design was used to evaluate the NDSS using updated CDC Guidelines for Surveillance System Evaluation. Health personnel involved in the NDSS were selected to participate in the evaluation. These included nurses, doctors, environmental health practitioners and health information officers. T1 forms were used in the records review. The study was carried out in all the 13 health facilities in Centenary District. Study participants who were on duty on the day of the interviews in rural health clinics were purposively recruited into the study. At the hospital health workers from admitting wards (female, male and maternity wards), Out-Patients department (OPD), Family Child Health $(\mathrm{FCH})$ and opportunistic infections department found on duty were also interviewed. District Health Executive members were purposively recruited as key informants. Using Dobson's formula, a minimum sample size of 59 health workers and $16 \mathrm{~T} 1$ forms was calculated. 
Interviewer administered questionnaire was used to interview health workers to establish reasons for not notifying notifiable diseases, to assess their knowledge on the NDSS, usefulness, simplicity and acceptability of the system. Checklists were used to assess the system's stability and data quality of the system. T1 forms were reviewed to check on data quality, acceptability and timeliness of the system. Epi Info $7^{\mathrm{TM}}$ was used to generate means, proportions and frequencies.

Permission to carry out the study was obtained from the institutional review board at Provincial Medical Directorate Mashonaland Central as well as from the Health Studies Office. Informed written consent was obtained from all the interviewees' separately. Confidentiality was maintained and assured throughout the study by not using interviewees' names instead anonymous numbers to identify questionnaires were used.

\section{Results}

From a calculated sample size of 59, we managed to recruit 50 health care workers as study participants yielding $84.7 \%$ response rate, and four managers were recruited as key informants. Demographic characteristics of all the study participants were assessed as summarised in Table 1 . Of the 50 participants recruited, 64\% ( $\mathrm{n}=32$ ) were females. The majority of respondents were nurses, 80\% ( $\mathrm{n}=40)$, who were Registered General Nurses $(27.5 \%)$, State Certified Nurses (5\%) and Primary Care Nurses (67.5\%). The median years in service for all the participants was 8 with an interquartile range of 6 to $13.5\left(Q_{1}=6, Q_{3}=\right.$ 13.5).

\subsection{Knowledge on NDSS}

A six point Likert scale was used to assess knowledge level using six variables. Fifty two percent knew what a notifiable disease is, $40 \%(\mathrm{n}=20)$ knew forms are completed in triplicate and $26 \%(n=13)$ knew whom to notify. Out of the 50

Table 1. Demographic characteristics of health workers in centenary district, Mashonaland central province, 2016.

\begin{tabular}{ccc}
\hline Characteristic & Frequency $\mathbf{n}=\mathbf{5 0}(\mathbf{\%})$ \\
\hline Sex & Male & $18(36)$ \\
& Female & $32(64)$ \\
Designation & Doctor & $1(2)$ \\
& Nurse (s) & $40(80)$ \\
& Environmental Health & $7(14)$ \\
Technicians (EHTs) & $1(2)$ \\
& Laboratory Technician & $1(2)$ \\
Median years in & Health Information Officer & $8\left(\mathrm{Q}_{1}=6, \mathrm{Q}_{3}=13.5\right)$ \\
service (IQR) & & \\
\hline
\end{tabular}


respondents, 28 (56\%) mentioned less than five notifiable diseases, $32 \%$ mentioned five to eight diseases and only $12 \%$ mentioned above nine notifiable diseases and (26\%) mentioned that notification is done to the District Medical Officer $(D M O)$. The study showed that $58 \%(n=29)$ had poor knowledge, $30 \%(n=$ $15)$ had average knowledge and $12 \%(n=6)$ had good knowledge. Overall rating of knowledge on NDSS in Centenary district was poor among health care workers. Table 2 shows knowledge assessment summary.

\subsection{Systems Attributes}

- Simplicity

Simplicity was assessed by looking at the proportions of health workers who can easily describe the completing of the $\mathrm{T} 1 \mathrm{form}$ and assess time needed to complete $\mathrm{T} 1 \mathrm{form}$. The researcher completed the form whilst being timed and also determined how many minutes it takes to complete the T1 form. Fourteen $(28 \%)$ had ever completed a $\mathrm{T} 1$ form, of which $64.2 \%(\mathrm{n}=18)$ reported having completed the form in less than 10 minutes. Four of the respondents were timed whilst completing the form and it took an average of four to six minutes and the researcher took about four minutes completing the form. Two (14\%) of the respondents reported difficulty in completing the form and cited the diagnosis section as the difficult area.

- Stability

Stability was assessed by looking at number of staff trained in NDSS, presence of functional transport and/or communication equipment and stationery avail-

Table 2. Knowledge of health workers on NDSS, centenary district, Mashonaland central province, 2016.

\begin{tabular}{|c|c|c|}
\hline Variable & Category & Frequency $n=50(\%)$ \\
\hline $\begin{array}{l}\text { Knowledge on what a } \\
\text { notifiable disease is }\end{array}$ & & $26(52)$ \\
\hline $\begin{array}{l}\text { Knowledge of form } \\
\text { used to report }\end{array}$ & & $22(44)$ \\
\hline $\begin{array}{l}\text { Number of forms completed } \\
\text { for notification }\end{array}$ & & $20(40)$ \\
\hline Whom to notify & & $13(26)$ \\
\hline $\begin{array}{c}\text { Knowledge of the required } \\
\text { time frame }\end{array}$ & & $40(80)$ \\
\hline \multirow[t]{3}{*}{$\begin{array}{l}\text { Knowledge of the notifiable } \\
\text { diseases }\end{array}$} & Mentioned $<5$ & $28(56)$ \\
\hline & Mentioned 5 to 8 & $16(32)$ \\
\hline & Mentioned > 9 & $6(12)$ \\
\hline \multirow[t]{3}{*}{ Overall knowledge rating } & Poor & $29(58)$ \\
\hline & Fair & $15(30)$ \\
\hline & Good & $6(12)$ \\
\hline
\end{tabular}


ability at the health centre. Out of the fifty participants $10 \%(\mathrm{n}=5)$ received on job training in NDSS and 10\% $(n=5)$ received 5 day training in Integrated Disease Surveillance and Response (IDSR). Those trained in IDSR were trained in 2011 (2\%), 2012 (4\%) and 2014 (4\%). All health facilities had standard case definitions, however only four (30\%) had at least six case definitions. Thirteen health facilities (100\%) reported using cell phones for reporting however, two health facilities had non-functional handsets and had improvised to using personal handsets. Three health facilities reported using the Environmental Health Technicians (EHTs) motorcycle for transportation of the T1 form to the district level and ten used public transport.

- Data Quality

It was measured by assessing the completeness and correctness of entries on the $\mathrm{T} 1$ forms. Twenty six forms were reviewed in this study. Of the 26 forms reviewed, $92 \%(n=24)$ of the forms were notifying suspected rabies cases. Eight forms did not have the name of the district, two forms did not have the diagnosis of the case and two forms did not have the reporting facility name. Table 3 shows the summary of the review.

- Acceptability

Ninety two percent of the respondents $(n=46)$ were willing to participate in the NDSS, and $90 \%(n=45)$ reported that they felt it was their duty to notify. Four of the respondents (8\%) were not willing to participate stating that the EHT, sister in charge and community sister were responsible for notification.

- Timeliness

Forty (80\%) of the respondents knew reporting is done in 24 hours of diagnosis of the notifiable disease. All the $\mathrm{T} 1$ forms reviewed were completed on the date of diagnosis. However there was no information on when notification was done by phone or when the forms reached the district

- Sensitivity

One suspected typhoid outbreak was reported in Centenary district from January to December 2016, though this was not notified using the T1 forms. Two out of the twelve cases were missed at the primary health care centre and were diagnosed at the district level.

- Flexibility

Review of the T1 forms show that the section on diagnosis is open which allows notification of any new disease that is added such as SARS and Human Influenza type A.

Table 3. Data quality of NDSS in centenary district, Mashonaland central province, 2016.

\begin{tabular}{ccc}
\hline Variable & Frequency $\mathbf{n}=\mathbf{2 6}(\%)$ \\
\hline Forms completely filled & & $18(69.2 \%)$ \\
Forms correctly filled in all sections & & $18(69.2 \%)$ \\
Areas incorrectly filled & Name of district & $8(30.7)$ \\
& Reporting facility & $2(7.7)$ \\
& Diagnosis of the case & $2(7.7)$ \\
\hline
\end{tabular}




\section{- Usefulness}

Respondents were asked what the collected data was used for, and what public health actions or decisions have been carried out or made based on the findings from data collected by the surveillance system. All the respondents (100\%) reported that the system was useful, and that they had used the data for action at facility level. However eight of the 13 health facilities had reports of the actions taken and minutes of the meetings held.

\subsection{Reasons for Not Notifying Notifiable Diseases}

The respondents were asked to state the reasons that caused failure to notify at their health facilities. The responses are summarised as shown in Figure 2. Sixty percent $(n=30)$ of the respondents stated lack of knowledge, $32 \%(n=16)$ unavailability of forms and $16 \%(n=8)$ lack of reporting guidelines as the main reasons for failure to notify notifiable diseases. Transport challenges and communication challenges were cited by $10 \%(n=5)$ of the respondents each.

\subsection{Cost of Operating the System}

The cost of notifying a single case of a notifiable disease using the T1 forms averages $\$ 17.92$, while that of using electronic means such as a cell phone costs about $\$ 1.52$ if adapted.

\section{Discussion}

Knowledge on NDSS in Centenary district was low. Poor knowledge may result in cases of notifiable diseases being missed, underreporting and mismanagement of cases. Lack of training may have caused the low knowledge levels as this study found that the majority of health workers were not trained. The health workers

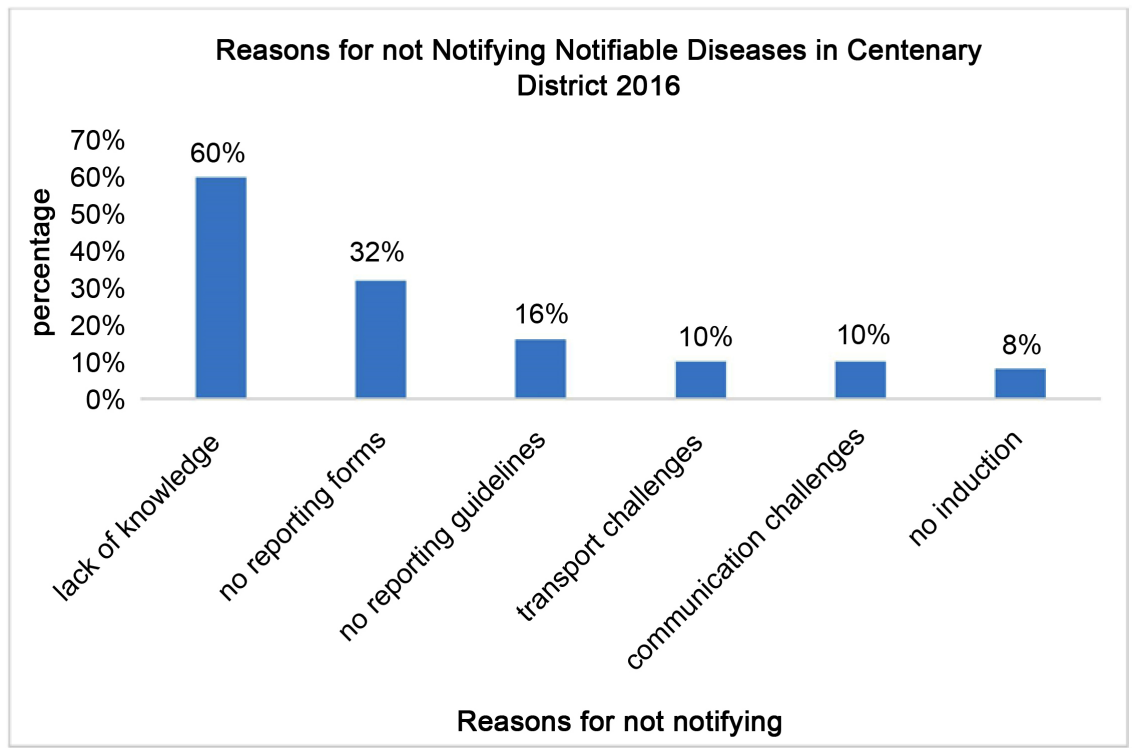

Figure 2. Reasons for not notifying notifiable diseases in centenary district, Mashonaland central, 2016. 
highlighted that they needed training so that they gain knowledge. It is essential that health workers are knowledgeable on the surveillance system so that they are able to identify, correctly diagnose and timeously notify notifiable diseases as this assists in prompt disease investigations and control, thereby minimising outbreaks. In a similar study done by Maponga et al. (2011) in Sanyati district low knowledge was attributed to lack of training [5]. Maponga et al. (2011) stated that low knowledge can result in health workers having a low index of suspicion of cases or failing to report notifiable diseases [5]. In Beitbridge district, Juru et al. (2015) also found out that not knowing the right form to use can have a resultant negative bearing on ability to notify diseases of public health importance [6]. In Nigeria a study done by Lafond et al. (2014) on reporting of notifiable diseases, showed that low knowledge on to whom they would report first affected effectiveness on identification and reporting of notifiable diseases thereby failing to notify notifiable diseases timeously [7].

In Centenary district the NDSS was found to be useful although health worker knowledge on the surveillance system was low. The district used data at local level to implement actions for disease control. In a suspected outbreak of typhoid in Gatu Township actions included, emptying of overwhelmed septic tanks, clean up of roads, replacement of sewer pipes, awareness campaigns on typhoid and prohibition of street vendors from selling food stuffs. Surveillance data was also used to control an anthrax outbreak in Mukombwe village (2015), where villagers were eating meat from dead hippopotamus. One health facility (Chawarura clinic) procured anti-rabies vaccine using Result Based Finance Funds for suspected rabies cases as the cases were rapidly increasing. The district also involved the veterinary department in the handling of the rabid dogs. Education was given to communities on the notifiable diseases following identification of some suspected cases. Similar findings were observed by Maponga et al. (2011) in which there was evident use of NDSS data in planning and mobilizing resources for Emergency Preparedness and Response, repair of radio communication systems and vaccination of dogs and cattle in rural Sanyati, following reports of outbreaks [5].

The NDSS is not stable. Notification of notifiable diseases remains a challenge in the district, although the key informants reported that there is adequate staffing at all health facilities to run the NDSS. Some of the cadres who received on job training in NDSS and training in IDSR still exhibited low knowledge. Those trained in IDSR reported having difficulties comprehending the training content as it was too complex that they still have difficulties in implementing. Contrary to findings by Maponga et al. (2011) that showed that those trained in IDSR had greater knowledge on notifiable diseases [5]. Training materials need to be simplified to ensure good understanding and improved knowledge levels. All health facilities reported using cell phones for reporting however, mobile network challenges were experienced at two health facilities, with one facility resorting to using the Mozambique network. Facing challenges in communication may cause 
failure to notify or delay in notification. This results in delayed outbreak investigations and control of diseases. Three health facilities reported using the EHTs motorcycle for transportation of the $\mathrm{T} 1$ forms to the district level and ten use public transport, use of public transport posed challenges to five of the health facilities in rainy season as the roads get slippery and access by public transport is impeded. None of the health facilities had at least $15 \mathrm{~T} 1 \mathrm{forms}$, which are adequate to notify the first five cases in case of an outbreak. Non availability of $\mathrm{T} 1$ forms can discourage a health worker from notifying, further delaying outbreak investigations.

The NDSS is acceptable in the district. Forty six (92\%) are willing to participate however the majority have referred patients to the EHT for notification as it seems is the common practice in the district. This is consistent with findings from Juru et al. where majority of respondents placed responsibility of reporting on EHTs. Though acceptability is high amongst the health workers in this study, performance of NDSS remains poor. Forty five-90\% acknowledged that reporting was in line with their duties and this is consistent with the study by Maponga et al. (2011) where acceptability was $100 \%$ but the performance remained low [5]. Low performance could be due to lack of reporting guidelines. In Nigeria a study by Lafond et al. (2014), suggested that in order to effectively identify and report notifiable diseases, reporting system requirements need to be clearly communicated to the participating health personnel and this improves the notification of the notifiable diseases [7].

In Centenary district the NDSS is simple, although, most health workers needed training to improve their understanding of the processes involved. Health workers perception of the system in regards to simplicity is important since if they perceive the system to be simple they will be motivated to notify thereby reducing missed cases. The NDSS is not sensitive, in 2016 two suspected cases of typhoid were missed at the primary health care level. These cases were identified at district and provincial level though they were not notified using the T1forms. This delayed investigation and control of the disease increasing the duration of transmission in the community.

The cost of notifying a single case of a notifiable disease using the T1 forms averages $\$ 17,92$, while that of using electronic means such as a cell phone costs about $\$ 1.52$ if adapted. The cost on paper based reporting could be reduced by adopting electronic means such as using cell phone platforms or electronic mailing, since the bigger portion of the paper based reporting cost is on travelling expenses and time consumed. This is consistent with findings of a study done by Juru et al., 2015 [6].

\section{Conclusion}

Knowledge among health workers in the district was low. Main reasons for not notifying cases were lack of knowledge among health workers and unavailability of reporting forms. The NDSS in Centenary district was found to be useful, simple, 
acceptable, not timely, unstable and not sensitive. Information sharing was done after each interview to correct misconceptions and two health facilities which did not have any $\mathrm{T} 1$ forms were given three copies each and were encouraged to reproduce at their health facilities. Fifteen IEC materials for case definitions on NDSS and reporting guidelines were distributed to five health facilities. We recommend that, health workers be trained in IDSR to ensure that they have knowledge on the processes involved and what actions to take. Follow up mentoring to be done to the health workers to ensure correct processes are followed.

\section{Acknowledgements}

The authors acknowledge the support received from Mashonaland Central Province, Health Studies Office and CDC Zimbabwe. Warm gratitude goes to colleagues for the support and guidance during the study.

\section{Competing Interests}

The authors declare that they have no competing interests.

\section{Authors' Contribution}

All authors were responsible for the conception of the problem, design, data collection, analysis and interpretation and drafting of the manuscript.

\section{Funding}

The study was funded by Centres for Disease Control and Prevention, Atlanta Georgia.

\section{References}

[1] CDC. Updated Guidelines for Evaluating Public Health Surveillance System. Recommendations from the Guidelines Working Group (2001) MMWR.50 (RR-13), 135. https://www.cdc.gov/mmwr/prevew/mmwrhtml/rr5013a1.htm

[2] Miller-Keane (2003) Encyclopaedia and Dictionary of Medical and Nursing and Allied Health. 7th Edition, Elsevier, Saunders.

[3] Government of Zimbabwe, Public Health Act.

[4] World Health Organisation, Centres for Disease Control and Prevention (2010) Technical Guidelines for Integrated Disease Surveillance and Response in the African Region. Brazzaville. Republic of Congo and Atlanta, USA, 1-398.

[5] Maponga, B.A., Chirundu, D., Shambira, G., Gombe, N.T., Tshimanga, M. and Bangure, D. (2014) Evaluation of the Notifiable Diseases Surveillance System in Sanyati District, Zimbabwe 2010-2011. The Pan African Medical Journal, 19, 278. https://doi.org/10.11604/pamj.2014.19.278.5202

[6] Juru, T.P., Nomagugu, N., Gombe, N.T., Tshimanga, M., Bangure, D., Mungati, M., et al. (2015) Evaluation of the Notifiable Disease Surveillance System in Beitbridge District, Zimbabwe 2015. Open Journal of Epidemiology, 5, 197-203. https://doi.org/10.4236/ojepi.2015.53024

[7] Lafond, K.E., Dalhatu, I., Shinde, V., Ekanem, E., Ahmed, S., Peebles, P., et al. 
(2014) Notifiable Disease Reporting among Public Sector Physicians in Nigeria: A Cross-Sectional Survey to Evaluate Possible Barriers and Identify Best Sources of Information. BMC Health Services Research, 14, 568.

https://doi.org/10.1186/s12913-014-0568-3

\section{Scientific Research Publishing}

Submit or recommend next manuscript to SCIRP and we will provide best service for you:

Accepting pre-submission inquiries through Email, Facebook, LinkedIn, Twitter, etc. A wide selection of journals (inclusive of 9 subjects, more than 200 journals)

Providing 24-hour high-quality service

User-friendly online submission system

Fair and swift peer-review system

Efficient typesetting and proofreading procedure

Display of the result of downloads and visits, as well as the number of cited articles Maximum dissemination of your research work

Submit your manuscript at: http://papersubmission.scirp.org/

Or contact ojepi@scirp.org 